\title{
A National Survey in Belgium on Post-ICU Follow-up Program
}

\author{
Danielle Prevedello, MD, MBA* (D) Fabio Silvio Taccone, MD, PhD and Jean-Charles \\ Preiser, MD, PhD $\mathbb{D}$
}

Department of Intensive Care Medicine, Erasme University Hospital, Brussels, Belgium

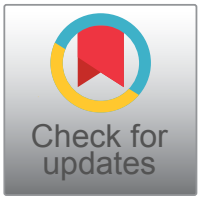

*Corresponding author: Danielle Prevedello, MD, MBA, Department of Intensive Care Medicine, Erasme Hospital, Route de Lennik 808, 1070 Anderlecht, Belgium, Tel: +32(0)2-555-5855

\begin{abstract}
Background: As the mortality in critical care patients reduces, post-intensive care syndrome grows as a public health concern, specially following outbreaks. Consequently, to address that problem, post-ICU follow-up programs emerged as a possibility to understand the long-term outcomes better and support ICU survivors. This study aims to state the prevalence of those programs in Belgium and comprehend how Belgians manage the care of ICU survivors.
\end{abstract}

Methods: We performed a national survey in Belgium on the management and current practices concerning the post-intensive care follow-up. The Belgian Society of Intensive Care endorsed this research. This survey had two validation processes (questionnaire validation by experts and questionnaire applicability by the pilot phase) following by the executive phase: Electronic distribution of the questionnaire to the ICU directors.

Results: Forty-three percent (36/82) of ICU directors responded to our electronic questionnaire. Six centers $(17 \%)$ currently run an ICU follow-up clinic. The first ICU follow-up clinic reported in Belgium was established in 2017. All clinics were composed by a multidisciplinary team, which had as responsible, in the majority of cases, a physician. The tools used to assess survivors diverged among centers; each center applied what they were familiar with or the tool that better fit their workload. The timing frame of consultations varied as well among centers. Three centers $(50 \%)$ presented only one consultation at three months after discharge and one center follows patients up to one year after discharge. Among those ICU departments that do not have an ICU follow-up program running currently, the majority would like to implement it. However, the lack of human resources and financial constraints were the two most frequent reasons mentioned that prevent centers from developing an ICU follow-up clinic.

Conclusion: A minority of Belgian ICUs ran a program to care for the ICU survivors. The ICU follow-up clinic's organization varied among centers, such as eligibility criteria and the tools to assess patients' impairments. The main obstacle for a post-ICU care program implementation was the lack of human and financial resources.

\section{Keywords}

ICU follow-up clinic Post-ICU follow-up, ICU rehabilitation program, Belgium survey

\begin{abstract}
Abbreviations
EAM: European Association of Methodology EQ-5D - EuroQol 5-dimensions; GP: General Practitioner; HRQoL: Health-related Quality of life; ICU: Intensive Care Unit; LOS: Length of Stay; MV: Mechanical Ventilation; PICS: Post-Intensive Care Syndrome; QoL: Quality of life; SF-36: 36-item Short form Health Survey SIZ - Belgian Society of Intensive Care; WAPOR: World Association for Public Opinion Research
\end{abstract}

\section{Introduction}

As the critically ill patients' mortality decreases, the concern about the burden from survival enhances. The term "post-intensive care syndrome" (PICS) nowadays encompasses all the impairments in the patients' mental, cognitive, or physical (physical and pulmonary function) status after critical illness and persisting beyond the acute hospitalization [1-5]. The prevalence of those disorders varies in the literature [6-11]. Patients might present symptoms from one, two, or even from the three categories at the same time $[12,13]$. The critical illness also impacts patients' quality of life after hospital discharge, even after physical rehabilitation, their quality of life persists lower than the general population [14-17].

The earliest ICU follow-up clinic reported in the literature was established in 1985 in the United Kingdom

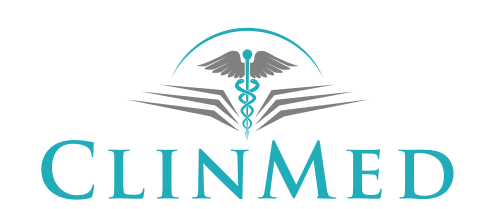

INTERNATIONAL LIBRARY 
to identify and rehabilitate patients after the acute critical illness [18]. Lately, the concept of an ICU follow-up clinic focusing on evaluation and rehabilitation of intensive care survivors has emerged across the world. Despite the increasing concern about ICU survivors and their health-related quality of life, there is no international consensus to describe the ideal model to deliver care after ICU discharge, neither there is enough scientific evidence to support current models adopted in post-ICU follow-up [19-22]. Instead, each hospital or country establishes its program, relying on its policies, regulations, and resources [23].

In Belgium, there are no standard guidelines for the care of ICU survivors after hospital discharge. Likewise, there is no register on the prevalence of Belgian ICUs engaged in that sort of program and neither how they perform this long-term follow-up. Within this national survey, we aimed to assess Belgium's reality about ICU survivor's management and their current follow-up programs.

\section{Methods}

We conducted a national survey in Belgium to assess the implementation of programs for ICU survivors. Questions addressed the following issues: The frequency of implementation of those programs, their organization, and how their potential utility was perceived. This survey was designed based on the International Handbook of Survey Methodology sponsored by the European
Association of Methodology (EAM) [24], the Survey Methods and Practices from Statistics Canada's National Centre [25], and the Revised WAPOR Code of Ethics, 2011. The survey has been approved by the Institutional Review Board of Erasme Hospital (IRB: P2018/443) and is endorsed by the Belgian Society of Intensive Care (SIZ).

We developed the research protocol which initially had its content validated by four experts [26]. They held a Ph.D. and MD credentials and had at least ten years of experience carrying out research. Three experts were specialists in intensive care medicine, and one expert was a specialist in the methodology of surveys and questionnaires.

A second validation was established with a pilot test. The method applied was stratified random sampling. We compose a sample per the geographical distribution of Belgian hospitals. Ten percent of hospitals in each region (Flanders, Wallonia, and Brussels) were included. Besides, to avoid sampling error, we electronically randomized the choices of each unit by using Microsoft Excel software. The following formula was used: $=R A N$ DBETWEEN (1, the total number of hospitals in each region) and F9 to continue the randomization until the exact number of services completes the sample.

After all the validation process, in March 2019, the questionnaire and the cover letter were addressed to all directors of ICUs in Belgian hospitals electronically. One

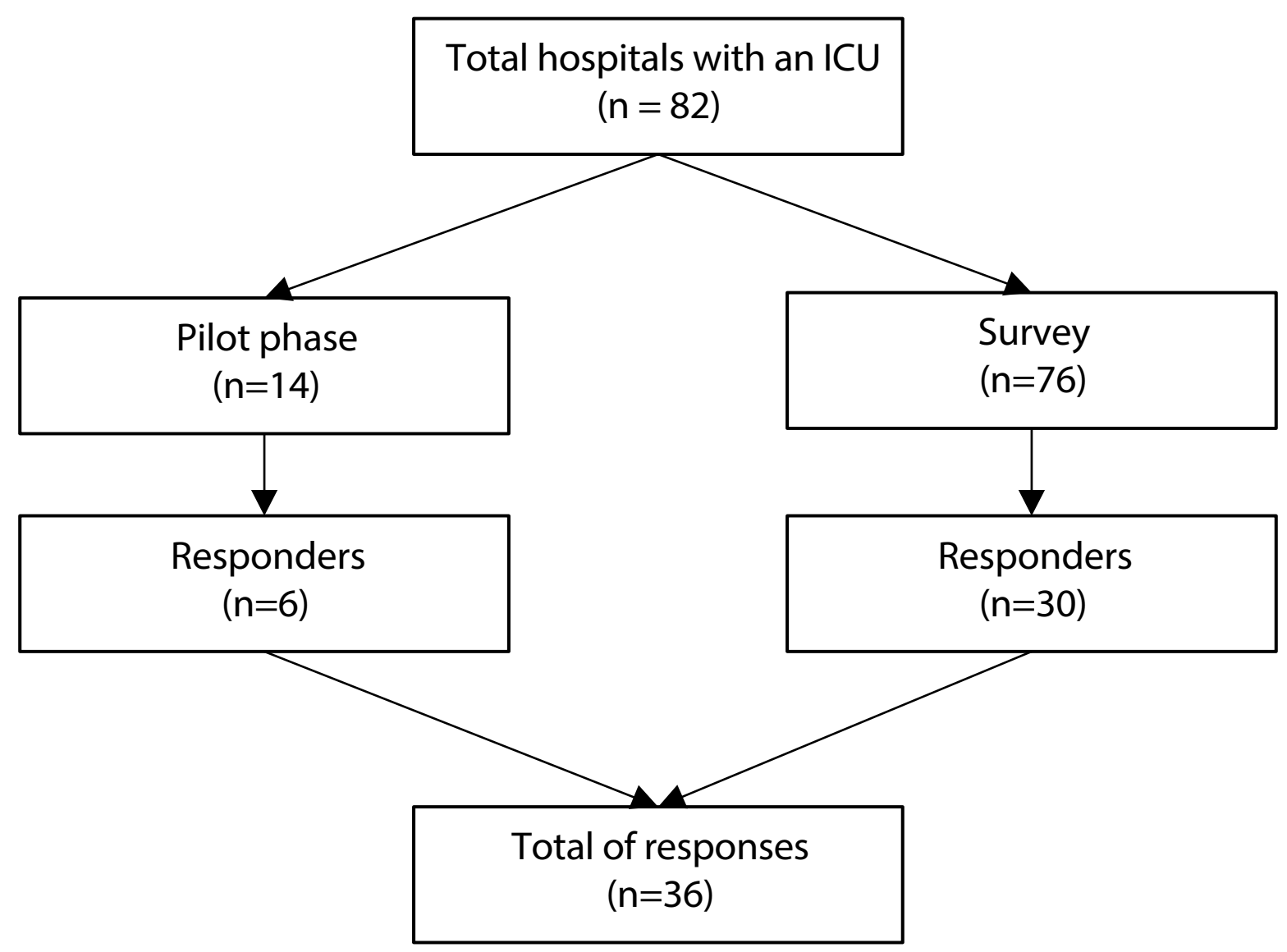

Figure 1: Flowchart of survey distribution stages and response rates. 
questionnaire percenter. Hospitals with more than one site, only one site was considered to participate. The questionnaire was anonymous. Two weeks following the distribution, a reminder letter and the link to access the questionnaire were resent by email. Eight months later, a new reminder was sent by the Belgian Society of Critical Care, trying to increase the response rate.

\section{Results}

\section{Summary of participating centers}

Thirty-six from 82 distributed surveys were answered, indicating an overall response rate of $43 \%$ (Figure 1). Specifically, each region in Belgium (Flanders, Wallonia, and Brussels) contributed 35\% (16/46), 46\% $(12 / 26)$, and $80 \%(8 / 10)$ of responses, respectively. The characteristics of responders are shown in Table 1 . Six centers (17\%) have an ICU follow-up program currently running. The first ICU follow-up clinic reported in Belgium was established in 2017 in the Flanders Region. Since then, one was established in 2018 in Brussels, following by two others in 2019 in Wallonia. Two responders did not specify the date of starting their program.

\section{ICU with follow-up program}

For all centers, the program was a multidisciplinary follow-up within at least two healthcare workers involved. The ICU follow-up clinic coordinator for the majority of responders was a physician (4/6). In centers nurse-led, a physician was available for the consultations, if requested. Four out of 6 centers worked with a physiotherapist in the team for a physical evaluation. Another healthcare worker often presents in the follow-up was a psychologist. In three out of 6 centers, the patients could discuss their emotions and feelings with a specialist.

The eligibility criteria to participate in the follow-up consultations varied among centers. However, a higher number of centers adopted the ICU length of stay (LOS) and the mechanical ventilation (MV) use as inclusion criteria. The most frequent outcome evaluated during

Table 1: Demographic characteristics of the responders per region.

\begin{tabular}{|l|l|}
\hline Characteristic & N (\%) \\
\hline Response rate according to Belgian region & \\
\hline Flanders & $16(44.5 \%)$ \\
\hline Wallonia & $12(33.3 \%)$ \\
\hline Brussels-Region & $8(22.2 \%)$ \\
\hline Type of hospital & \\
\hline University hospital & $7(19.5 \%)$ \\
\hline General hospital & $21(58.3 \%)$ \\
\hline University-affiliated & $8(22.2 \%)$ \\
\hline Status of the hospital & \\
\hline Private & $8(22.2 \%)$ \\
\hline Public & $28(77.8 \%)$ \\
\hline
\end{tabular}

consultations was the health- related Quality of life (HRQoL), which was assessed with the 36-item Short-Form Health Survey (SF-36) or with the EuroQol 5-dimensions (EQ-5D). For other patients' functional recovery, locally derived questionnaires were the tools most frequently used.

Regarding the consultations' timing frame, for three centers, the follow-up consultation was offered only once. For two centers, patients attended two consultations, finishing at six months after ICU or hospital discharge. One center followed the patients three times up to one year after discharge. After the ICU follow-up consultations in all centers, patients could be referred to a specialist if needed. The most common specialist was a clinical psychologist. Two centers involved the general practitioner (GP) as a vital role in decision-making for the patient. The GPs are responsible for referring patients to a specialist if deemed appropriate.

Regarding the financial aspect of the ICU follow-up clinic, only one center was funded with external or private rewards. The other five centers do not have any specific funds. Two departments used the budget of the hospital to afford the ICU follow-up activities partially.

\section{ICU without follow-up program}

Thirty centers out of 82 (83.0\%) did not run an ICU follow-up clinic currently. For those, we sought to understand why they did not have an ICU follow-up program implemented, and if they would like to have one. Although 26 centers (86.6\%) were interested in starting an ICU follow-up clinic, the lack of human resources (20/30 66.6\%) and financial constraints (12/30 40.0\%) were the main restrictions (Table 2 ).

\section{Discussion}

This survey showed that ICU follow-up clinics are not common in Belgium, in spite of a growing interest towards PICS. The lack of financial support is the main obstacle that prevents the implementation of a program focusing on the care and rehabilitation of those patients. The health system in Belgium is particularly complex and differs from the public health provision in the UK and the private health system in the USA. Probably, the lack of a guidelines for the care of ICU survivors adapted to the Belgian health system reality is another relevant barrier that should be raised in future research.

Table 2: Reasons not to implement an ICU follow-up clinic.

\begin{tabular}{|l|l|}
\hline Obstacles* & N (\%) \\
\hline Lack of human resources & $19(63.3 \%)$ \\
\hline Financial constraints & $12(40.0 \%)$ \\
\hline Lack of current evidence for benefit & $5(16.6 \%)$ \\
\hline Lack of adequate place & $4(13.3 \%)$ \\
\hline Lack of clinical need & $2(6.6 \%)$ \\
\hline
\end{tabular}

*Possible to select more than one answer 
Although we achieved the possibility of sending the electronic questionnaire to the majority of ICU directors in Belgian hospitals, one limitation of our study is the response rate. Unfortunately, it only allowed an analysis of $43 \%$ of ICU departments. That makes us not be sure if the finding can be representative of the whole country.

In our survey, $17 \%$ of the centers had an ICU follow-up clinic currently with $67 \%$ in the physician-led structure. In a similar survey performed in 2006 by Griffiths, et al. in the UK, ICU follow-up clinics were present in $30 \%$ of the hospitals, and $55 \%$ were nurse-led [18]. Similar results were found in a survey conducted in the Netherlands and published in 2015, which showed that $40 \%$ of the centers had a follow-up for ICU survivors, and $70 \%$ were nurse-led [27]. In Denmark, a survey conducted in 2017 showed that $84 \%$ of the intensive care units had an ICU follow-up clinic running. The Scandinavian health system's organization can explain this higher implementation of a follow-up service in this country. They incorporated the ICU follow-up program into the standard care offered.

According to all surveys, the main barrier to provide an ICU follow-up program is the lack of resources (human and financial) [18,27-29]. In our survey, $40 \%$ of hospitals appointed funding as a problem, even among the centers running an ICU follow-up, 83\% were not funded. In 2014, after the recommendations for post-ICU rehabilitation been published in the UK, Connolly, et al. conducted a new survey which measured the adherence of British intensive care units to the national guideline (NICE CG83), and only $27.3 \%$ of the organizations had a post-ICU clinic, again been the critical limiting aspect the lack of source of funding.

In conclusion, this survey has shown an estimated number of Belgian ICU departments engaged in ICU survivors' care after hospital discharge. The majority of the ICU with the no-follow-up program would like to improve this service in their organization. However, the lack of funding is the primary limiting. New health policies and plans for ICU survivor's management should be developed and implemented.

\section{Acknowledgments}

We acknowledge the Belgian Society of Critical Care staff members for endorsing and disclosing this research.

\section{References}

1. Needham DM, Davidson J, Cohen H, Hopkins RO, Weinert C, et al. (2012) Improving long-term outcomes after discharge from intensive care unit. Crit Care Med 40: 502509.

2. Harvey MA, Davidson JE (2016) Postintensive Care Syndrome: Right Care, Right Now...and Later. Crit Care Med 44: 381-385.

3. Langerud AK, Rustøen T, Småstuen MC, Kongsgaard U, Stubhaug A (2018) Intensive care survivor- reported symp- toms: a longitudinal study of survivors' symptoms. Nurs Crit Care 23: 48-54.

4. Harvey MA (2012) The truth about consequences-Post-intensive care syndrome in intensive care unit survivors and their families. Crit Care Med 40: 2506-2507.

5. van der Schaaf $M$, Beelen A, Nollet $F$, Dongelmans DA (2012) Postintensive care syndrome, need for recognition, treatment, research, and expansion of included symptoms. Crit Care Med 40: 2742-2743.

6. Davydow DS, Gifford JM, Desai SV, Bienvenu OJ, Needham DM (2009) Depression in general intensive care unit survivors: A systematic review. Intensive Care Med 35: 796-809.

7. Nikayin S, Rabiee A, Hashem MD, Huang M, Bienvenu OJ, et al. (2016) Anxiety symptoms in survivors of critical illness: A systematic review and meta-analysis. Gen Hosp Psychiatry 43: 23-29.

8. Righy C, Rosa RG, Da Silva RTA, Kochhann R, Migliavaca CB, et al. (2019) Prevalence of post-traumatic stress disorder symptoms in adult critical care survivors: A systematic review and meta-analysis. Crit Care 23: 1-3.

9. Pandharipande PP, Girard TD, Jackson JC, Morandi A, Thompson JL, et al. (2013) Long-Term cognitive impairment after critical illness. N Engl J Med 369: 1306-1316.

10. Parker AM, Sricharoenchai T, Raparla S, Schneck KW, Bienvenu OJ, et al. (2015) Posttraumatic stress disorder in critical illness survivors: A Metaanalysis Crit Care Med 43: 1121-1129.

11. Jones C (2014) Recovery post ICU. Intensive Crit Care Nurs 30: 239-245.

12. Marra A, Pandharipande PP, Girard TD, Patel MB, Hughes CG, et al. (2018) Co-Occurrence of Post-Intensive Care Syndrome Problems among 406 Survivors of Critical IIIness. Crit Care Med 46: 1393-1401.

13. Bienvenu OJ, Colantuoni E, Mendez-Tellez PA, Shanholtz C, Dennison-Himmelfarb CR, et al. (2015) Cooccurrence of and remission from general anxiety, depression, and posttraumatic stress disorder symptoms after acute lung injury: A 2-year longitudinal study. Crit Care Med 43: 642-653.

14. Dowdy DW, Eid MP, Sedrakyan A, Mendez-Tellez PA, Pronovost PJ, et al. (2005) Quality of life in adult survivors of critical illness: A systematic review of the literature. Intensive Care Med 31: 611-620.

15. Myhren H, Ekeberg O, Stokland O (2010) Health-related quality of life and return to work after critical illness in general intensive care unit patients: A 1-year follow-up study. Crit Care Med 38: 1554-1561.

16. Angus DC, Carlet J (2003) Surviving intensive care: A report from the 2002 brussels roundtable. Intensive Care Med 29: 368-377.

17. Dowdy DW, Eid MP, Dennison CR, Mendez-Tellez PA, Herridge MS, et al. (2006) Quality of life after acute respiratory distress syndrome: A meta-analysis. Intensive Care Med 32: 1115-1124.

18. Griffiths JA, Barber VS, Cuthbertson BH, Young JD (2006) A national survey of intensive care follow-up clinics. Anaesthesia 61: 950-955.

19. Jensen JF, Thomsen T, Overgaard D, Bestle MH, Christensen D, et al. (2015) Impact of follow-up consultations for ICU survivors on post-ICU syndrome: A systematic review and meta-analysis. Intensive Care Med 41: 763-775. 
20. Mehlhorn J, Freytag A, Schmidt K, Brunkhorst FM, Graf J, et al. (2014) Rehabilitation interventions for postintensive care syndrome: A systematic review. Crit Care Med 42: $1263-1271$.

21. Williams TA, Leslie GD (2008) Beyond the walls: A review of ICU clinics and their impact on patient outcomes after leaving hospital. Aust Crit Care 21: 6-17.

22. Lasiter S, Oles SK, Mundell J, London S, Khan B (2016) Critical care follow-up clinics: A scoping review of interventions and outcomes. Clin Nurse Spec 30: 227-237.

23. (2017) National Institute for Heath and Care Excellence, NICE. Rehabilitation after critical illness in adults. Natl Inst Heal Care Excell 1-27.

24. de Leeuw ED, Hox J, Dillman D (2012) International Handbook of Survey Methodology. International Handbook of Survey Methodology.
25. Canada S (2010) Survey Methods and Practices. 1-408.

26. Prevedello D, Taccone F, Preiser JC (2018) National survey on the post-ICU Follow-up: PROTOCOL.

27. Van Schaaf M Der, Bakhshi-Raiez F, Van Der Steen M, Dongelmans DA, De Keizer NF (2015) Recommendations for intensive care follow-up clinics; Report from a survey and conference of Dutch intensive cares. Minerva Anestesiol 81: 135-144.

28. Connolly B, Douiri A, Steier J, Moxham J, Denehy L, et al. (2014) A UK survey of rehabilitation following critical illness: Implementation of NICE Clinical Guidance 83 (CG83) following hospital discharge. BMJ Open 4: 1-9.

29. Kjer CKW, Estrup S, Poulsen LM, Mathiesen O (2017) Follow-up after intensive care treatment: A questionnaire survey of intensive care aftercare in Denmark. Acta Anaesthesiol Scand 61: 925-934. 